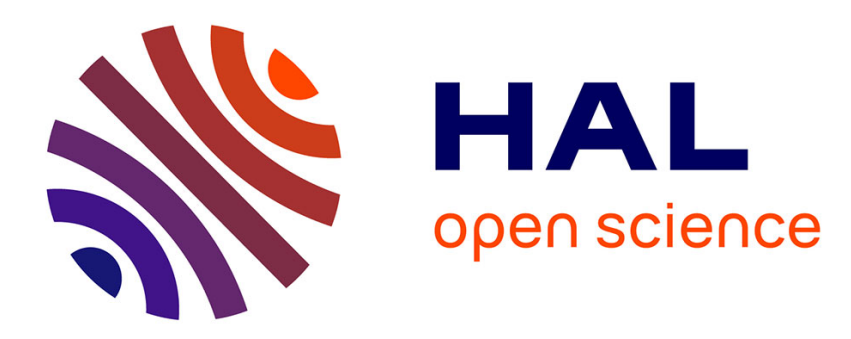

\title{
Waiting to Imitate: On the Dynamic Pricing of Knowledge
}

\author{
Emeric Henry, Carlos J. Ponce
}

\section{To cite this version:}

Emeric Henry, Carlos J. Ponce. Waiting to Imitate: On the Dynamic Pricing of Knowledge. 2011. hal-00972950

\section{HAL Id: hal-00972950 \\ https: / hal-sciencespo.archives-ouvertes.fr/hal-00972950}

Preprint submitted on 3 Apr 2014

HAL is a multi-disciplinary open access archive for the deposit and dissemination of scientific research documents, whether they are published or not. The documents may come from teaching and research institutions in France or abroad, or from public or private research centers.
L'archive ouverte pluridisciplinaire HAL, est destinée au dépôt et à la diffusion de documents scientifiques de niveau recherche, publiés ou non, émanant des établissements d'enseignement et de recherche français ou étrangers, des laboratoires publics ou privés. 


\title{
Waiting to Imitate: On the Dynamic Pricing of Knowledge
}

\author{
Emeric Henry and Carlos J. Ponce*
}

April 29, 2011

\begin{abstract}
We study the problem of an inventor who brings to the market an innovation that can be legally copied. Imitators may 'enter' the market by copying the innovation at a cost or by buying from the inventor the knowledge necessary to reproduce and use the invention. The possibility of contracting dramatically affects the need for patent protection. Indeed, our results reveal that: (i) Imitators wait to enter the market and the inventor becomes a temporary monopolist; (ii) The inventor offers contracts which allow resale of the knowledge by the imitators; (iii) The profits of the inventor typically increase with the number of potential imitators.
\end{abstract}

JEL: L24, O31, O34, D23, C73.

KEYwords: Patents, contracting, knowledge trading, delay, war of attrition.

\section{INTRODUCTION}

The economics of innovation revolve around the design and analysis of incentive schemes for inventors under the threat of imitation. The main premise is that, when knowledge is cheap to imitate, innovative rewards are vulnerable to ex-post expropriation by imitators. Imitators immediately copy the innovation, dissipating the rents of inventors and thus discouraging costly research. This reasoning justifies the need for patents and other legal means of protecting the inventors' profits.

Controversies, however, about the strength of intellectual property rights, the set of technologies that should be protected by intellectual property law and even the need for such a system have been recurrent over time. The essence of these debates is expressed in the following question raised by Gallini and Scotchmer (2001):

*Sciences Po, department of Economics, 28 rue des Saint Peres, 75007 Paris; and Departmento de Economia, Universidad Carlos III de Madrid, Madrid 126, 28903 Getafe, Spain, respectively. Emeric Henry acknowledges the support of the Agence Nationale Pour la Recherche through its program Chaire d'Excellence. 
Are there natural market forces that protect inventors so that formal protections or other incentives are not necessary?

This paper answers this question by providing theoretical foundations for a natural, intuitive and market-based mechanism which yields substantive rents for inventors in the absence of patent protection. Specifically, we reveal that the possibility of trading the knowledge which is necessary to develop and use the innovation fundamentally alters the 'conventional wisdom' on the need for patent protection.

The natural market force we identify is based on the dynamic trading of knowledge. As a preview of our main results, we note that, in equilibrium, potential imitators will obtain the innovation by buying knowledge rather than by spending duplicative resources on imitation. Furthermore, the inventor optimally chooses to sell knowledge through contracts which allow subsequent reselling by the buyers. Thus, the first buyer will compete with the inventor to sell his acquired knowledge to the remaining imitators. Therefore, initially, imitators have an incentive to delay their entry with the hope that some of their rivals will trade with the inventor before them, anticipating as a consequence a future fall in the price of knowledge. Temporarily the inventor becomes a monopolist and might receive a reward arbitrarily close to monopoly profits, even for relatively small imitation costs.

This paper therefore suggests that that the traditional justification for patent protection is overturned when knowledge trading is considered. Whereas the previous literature has focused on the profits after imitation (i.e., ex-post profits) as the main determinant of the inventors' payoff, we underline that the payoff received by inventors is determined by the difference between the ex-post profits after entry of all imitators and the imitation cost. If these two measures are similar, the temptation to wait becomes very large and the innovator becomes a permanent monopolist even in the absence of protection.

We insist on the fact that our paper does not claim that weakening patent protection would be welfare improving. We in fact predict, in section 5, very similar dynamics in the absence of patents as would occur with legal protection for both the path of entry of imitators and for the innovator's profits. When knowledge trades are feasible the innovator remains a monopolist for a certain time and, when entry finally occurs, all imitators simultaneously enter. The path of entry of imitators is thus observationally equivalent with or without patents. ${ }^{1}$ Our paper therefore provides a micro foundation for the way incentives to innovate are modeled in for instance the literature on growth and shows that indeed these models can be independent of the legal features and in particular do not need to assume the existence

\footnotetext{
${ }^{1}$ The main difference is that the length of monopoly is random under our mechanism while it is fixed by law in the case of patents.
} 
of patents. ${ }^{2}$

Boldrin and Levine (2002, 2005, 2008), focusing on a different type of mechanism, have also shown that there exists sources of rents for inventors even in the absence of patent protection. In their work, an inventor owns the unique initial prototype that can be used for both producing copies of the innovation and also for consumption. Each buyer of a copy can then in turn create new copies with a delay of one period. Therefore, in the future, the inventor will compete directly with the buyers of her copies. Their main point is that the price at which the scarce initial prototype is sold reflects the future revenue stream that it will generate.

Boldrin and Levine (2002, 2005, 2008) might be more directly applicable to copyrights: In their model, there exists a technology that costlessly produces a certain number of copies every period, like reproducing a book or a CD. Our approach is more relevant for the case of patents: Imitators have access to a profitable but costly reverse engineering technology to obtain the innovation. Our focus is thus on potential knowledge transactions to save wasteful reverse engineering activities; a dimension that is less relevant in the case of copyrights. We also make a clear distinction between two markets: The product market, from which the inventor receives the bulk of her rents, and the market for knowledge. In our setting the inventor does not compete with her own customers but rather with potential imitators who might 'steal' the inventor's customers.

Boldrin and Levine (2010) is also related and more relevant for the case of patents. They share with us the perspective that imitators are active agents who optimally choose whether or not to imitate in an environment with sunk imitation cost. However, while their goal is to show that the introduction of intellectual property might lead to a misallocation of resources between 'low' and 'high' quality discoveries, ours is to stress that, in the absence of patent protection, market forces yield an equilibrium delay that protect inventors from imitation.

The mechanism we study leads to delay in imitation. Other explanations for the existence of such delays have also been proposed. ${ }^{3}$ Benoit (1985) shows that a unique imitator might want to delay entry on the market if the profitability of her innovation is uncertain and gradually revealed over time. In Choi (1998) endogenous delay also occurs as a consequence of

\footnotetext{
${ }^{2}$ We point out that several papers in the literature on growth endogenize imitative efforts (Segerstrom (1991), Grossman and Helpman (1991), Davidson and Segerstrom (1999)). The situation they consider is one where firms strategically invest both in innovation and imitation. The model of imitation is typically such that an initial investment generates a Poisson arrival process for the imitated product. In these papers the delay between imitation and innovation is a technological one: the imitation process is a research process that is uncertain and takes time. Furthermore, entry by one imitator is not followed by cumulative entry of the others. In our paper the source of delay is on the contrary purely strategic and we predict grouped entry of all imitators as would be observed with patents.

${ }^{3}$ Scherer and Ross (1980) suggest that technological constraints generate 'natural lags' in imitation. This explanation does not depend on the strategic responses of imitators.
} 
the strategic interaction between imitators in a context of patent infringement suits brought by the patent holder. ${ }^{4}$ Note also that in static frameworks, some papers have shown that licensing can serve as a barrier to entry (Gallini (1984) and Rockett (1990)). In these papers, licensing is used to deter the development of a superior technology and to crowd out the market to prevent entry of superior rivals.

The market for knowledge is also the focus of Muto (1986). This paper shares with ours the focus on resale of information. However there are several major differences. First, in Muto (1986), an important restriction is imposed: If no sale occurs in a period, the game ends. This removes the possibility of waiting to enter. Second, imitation is not a possibility in that paper. As a consequence, naturally, it is optimal to restrict resale, both in terms of profits of the monopolist and in terms of diffusion rates.

The paper is organized as follows. In Section 2 we describe the model. In section 3, we present our main findings. We show how our mechanism leads to a natural protection for inventors and discuss the importance of transferable knowledge contracts as well as suggestive evidence. In Section 4 we extend our model to an arbitrary number of potential imitators. In section 5 we discuss how our model can be applied to the choice between patent protection and trade secrecy while in section 6 we examine whether the contracts we study are robust to moral hazard concerns. All proofs are presented in the Appendix.

\section{THE ModeL}

An inventor ('she'), denoted by $s$, has developed an innovation (process or product) that is not legally protected against imitation. Two imitators, indexed by $g \in\{j, l\}$, may 'adopt' the innovation by either: (i) Using a costly imitation technology (henceforth, imitating) or (ii) Buying knowledge from the inventor.

Time is broken into a countable infinite sequence of periods of length $\Delta>0$. Each period is indexed by $t(t=0,1 \ldots)$. The innovation is introduced into the product market at period zero. At that period, the imitators might already be producing in the market. Their profits if they do not use the innovation are normalized to zero. ${ }^{5}$

The following terminology will be used throughout the paper. When an imitator adopts the innovation at period $t$, we say that he enters the market regardless of his mode of entry.

\footnotetext{
${ }^{4}$ Bernheim (1984) also examines the dynamics of entry deterrence. The dynamics is however very different than in our model. In particular, Bernheim (1984) assumes that entrants are ordered in an exogenously given sequence. Arora and Fosfuri (2003) highlights that it may be optimal for a firm to license out its technology to a rival. This paper shares some similarities with what we have called the competitive game: The trade-off considered in that paper is comparable to the one that guarantees uniqueness of the no-delay contracting equilibrium in the competitive game.

${ }^{5}$ This is without loss of generality. The model can encompass either a drastic or non-drastic innovation.
} 
Also we describe him as active in the market from that period on. The inventor and each active imitator obtain the same equilibrium profit flow independently of how the imitators entered. The profit flow received by each individual firm when $n-1$ other firms are also active is denoted by $\pi_{n}{ }^{6}$

All parties are risk neutral and maximize the sum of their expected discounted payoffs (profits plus potential contract payments). Agents discount the future exponentially with a per-period discount factor equal to $\delta \equiv e^{-r \Delta}$, where $r>0$ is the discount rate. So, the profits received by each individual firm during a period in which $n-1$ other firms are also active is $\int_{0}^{\Delta} \pi_{n} e^{-r t} d t=(1-\delta) \Pi_{n}$; where $\Pi_{n} \equiv r^{-1} \pi_{n}$ is the present value of market profits per firm when $n$ firms are active. We assume that profits satisfy the following standard condition:

Assumption 0: $\Pi_{1}>2 \Pi_{2}>3 \Pi_{3}$

An imitator by spending, at any period $t$, an amount of resources $\kappa>0$ obtains instantaneously (at the same period) a perfect version of the innovation. We view $\kappa$ as a one-time sunk cost that must be incurred to reverse engineer the fine details of the innovation. An alternative to imitation is to enter the market by buying knowledge through contracting. The inventor, being the creator of the innovation, possesses the required (indivisible) knowledge to transfer the innovation. If an imitator buys this piece of knowledge at $t$, he will be able to instantaneously obtain a perfect version of the innovation at zero added cost.

Contracting takes place as follows. At any $t$, before entry, a fix-fee contract between the inventor (seller) and imitator $g$ (buyer) is a pair $\left(p_{s g}^{t}, \theta_{s g}^{t}\right) \in[0, \infty] \times\{0,1\} . p_{s g}^{t} \geq 0$ is the price at which the inventor offers a contract of type $\theta_{s g}^{t}$ to imitator $g$ at $t$. Two types of contracts can be offered: Non-transferable, $\theta_{s g}=0$, and transferable contracts $\theta_{s g}=1$. A transferable contract allows an imitator to resell the knowledge acquired from the inventor to the other imitator in subsequent periods. The following convention is adopted: Offering no contract to imitator $g$, at period $t$, is equivalent to offering a contract at $p_{s g}^{t}=\infty$. Last, we also assume that if an imitator enters by imitating, he will also become a competitor of the inventor in the knowledge market. Specifically, at each $t$, in which only one imitator, say $j$, is active in the market and entered either by imitation or by buying a transferable contract, he and the innovator offer a contract at a price $p_{j l}^{t}$ and $p_{s l}^{t}$ to imitator $l$ respectively.

Potential knowledge exchanges occur within the framework of the following extensive form game. Consider any period $t$ in which no imitator has entered yet. Then:

(i) The inventor announces, on a take-it-or-leave-it basis, a pair of contracts, $\left\{p_{s g}^{t}, \theta_{s g}^{t}\right\}$ for $g \in\{j, l\}$. Then:

\footnotetext{
${ }^{6}$ To make our arguments most general profits are specified in reduced form.
} 
(ii) The imitators simultaneously decide whether to enter the market -either by imitating, $i_{g}$, or by buying knowledge through contracting, $c_{g^{-}}$or not to enter, $w_{g}$.

The game continues in this manner as long as no imitator enters the market. If, at period $t$, both imitators enter, the game formally ends and all players collect triopoly profits from that period on. But if only one of them enters, say $j$, from the beginning of period $t+1$ until entry of the second imitator the game continues as follows:

(i) The sellers simultaneously announce prices for knowledge: $p_{j l}^{t+\tau}$ and $p_{s l}^{t+\tau}$ respectively, for all $\tau=1,2 \ldots$ If imitator $j$ bought a non-transferable contract at $t$, the convention is that $p_{j l}^{t+\tau}=\infty$ for all $\tau=1,2 \ldots$ Then:

(ii) Imitator $l$ decides whether to enter the market -either by imitating, $i_{l}$, or by buying knowledge from one of the sellers, $c_{j l}$ or $c_{s l^{-}}$or not to enter, $w_{l}$.

All parties observe the history of the game up to the beginning of period $t$ and the buyer(s) observe the contract(s) offered by the seller(s) at the beginning of period $t$.

We use Subgame-Perfect equilibria (SPE) and Markov Perfect Equilibria (MPE) as solution concepts. In MPE strategies are functions only of payoff-relevant histories which are determined in our model by the number of buyers and sellers in the market for knowledge contract. So we cluster all possible histories, according to the market structure, into three disjoint and exhaustive subsets: (i) The subset of all histories in which the inventor is the unique seller and the imitators are the buyers. Such a subgame is called the monopoly game; (ii) The subset of all those histories in which the inventor and one of the imitators are the sellers. Such a subgame is called the competitive game; and last: (iii) The remaining subset of histories in which the inventor is the unique seller and there is a unique buyer. ${ }^{7}$ Such a subgame is called the bilateral monopoly game. Then a MPE is a SPE in which the contracting strategy of the inventor is only a function of the market structure and the entry-decision functions of the imitators depend only on the prices and type of contracts being offered.

\section{Main Results: Appropriation without Patents}

\section{A. Innovative Rents without Knowledge Trading}

As a benchmark, we analyze the dynamics of entry when contracting is not feasible. Thus, if potential imitators choose to enter they must do so by imitating. Although we consider an economy without patents, the imitation cost works as an entry barrier determining a natural measure of protection for the inventor. A value of $\kappa$ such that $\kappa>\Pi_{2}$ is sufficient to fully protect the inventor from imitation. Thus, to make our problem interesting, Assumption $1 .^{8}$

\footnotetext{
${ }^{7}$ This corresponds to the case in which only one imitator previously entered by buying knowledge through a non-transferable contract.

${ }^{8}$ In section 4 we extend Assumption 1 to the case of a large number of imitators.
} 
Assumption 1: $0<\kappa<\Pi_{3}$

Assumption 1 ensures that copying is profitable for both imitators. Under this assumption, we obtain the following result:

Proposition 1 If knowledge cannot be traded, then: (i) There is a unique SPE in which both imitators imitate at period $t=0$; and: (ii) The equilibrium payoffs for the inventor and the imitators are $\Pi_{3}$ and $\Pi_{3}-\kappa$ respectively.

Proposition 1 shows that, when knowledge cannot be traded, both imitators enter the market immediately. Indeed there is no benefit from delaying entry since the entry cost will remain fixed at the level of the imitation cost. Moreover, by delaying entry, imitators sacrifice profits during the periods in which they do not use the innovation. Hence, if entry occurs it will take place at period zero. Assumption 1 ensures that entry does occur as it is profitable for both imitators.

Proposition 1 summarizes the 'conventional wisdom' justifying the need for patent protection. In the absence of such protection, imitators enter immediately and compete away the rents of the inventor. Foreseeing the risk that their reward might be insufficient to cover their research costs, inventors might thus shy away from initially investing in research.

\section{B. Appropriation With KNOWLEDGE TRADING}

We show that the results of Proposition 1 justifying patent protection are fundamentally altered when trades in knowledge are feasible. We start by focusing our attention on transferable contracts and next we demonstrate that, indeed, the inventor strictly prefers to sell knowledge through transferable rather than non-transferable contracts.

As we restrict our attention to the case of transferable contracts, after entering, an imitator competes with the inventor to sell knowledge to the remaining imitator. Thus, we only need to examine the competitive and monopoly subgames. ${ }^{9}$ First, we focus on the competitive game. Suppose that imitator $j$ has entered at period $t$. The sellers $(j$ and $s)$ may, in subsequent periods, offer contracts to the buyer $(l)$. The competitive subgame has a unique MPE that we call the no-delay contracting equilibrium.

Lemma 1 In the unique MPE of the competitive subgame, knowledge is sold to imitator $l$ immediately at period $t+1$ at a zero price.

\footnotetext{
${ }^{9}$ If both imitators enter simultaneously the entry game ends and players collect triopoly profits at every period.
} 
Competition immediately drives the price of knowledge to zero. The intuition for the result of Lemma 1 is the following: A contract is necessarily signed at some point in time since the last imitator always has the option to enter on his own by paying the imitation cost. When the contract is signed, the price has to be zero, due to competition between the sellers. In a MPE, the license is thus immediately signed. ${ }^{10}$ The fall in the price of knowledge following the entry of the first imitator is the key to the following result: ${ }^{11}$

Proposition 2 As $\Delta$ shrinks to zero, there exists a unique symmetric MPE in which:

(i) The inventor sets a price for knowledge $p_{\text {sg }}=\kappa$ for $g \in\{j, l\}$

(ii) The equilibrium distribution of entry times of each imitator converges to an exponential distribution with hazard rate equal to $\lambda=r\left(\Pi_{3}-\kappa\right) / \kappa$

(iii) The inventor's equilibrium expected payoff is $V_{s}=\mu(\kappa) \Pi_{1}+(1-\mu(\kappa))\left(\Pi_{3}+\kappa\right)$; where $\mu(\kappa):=r /(r+2 \lambda) \in(0,1)$.

Result (ii) shows that potential imitators wait a random length of time before entering the market. The intuition is as follows. According to result (i), the price of the knowledge sold through the first contract equals the imitation cost, $\kappa$. After the first sale, however, the equilibrium price of knowledge drops to zero due to competition in the knowledge market. Thus, as the length $\Delta$ between periods shrinks to zero, the payoff of the follower imitator becomes strictly greater than the payoff of the leader as he enters quasi simultaneously but does not pay for imitation. As a result, both players have an incentive to delay their entry. Delay is however costly as both imitators sacrifice current market profits. We have the conditions for a war of attrition where, in equilibrium, potential imitators randomize their entry time and where the limiting distribution is exponential with hazard rate equal to $\lambda .{ }^{12}$

The hazard rate, reflects the tradeoff, common to all war of attrition games, between delaying in the hope of being second and entering immediately to avoid forgoing profits. The cost of waiting corresponds to the lost payoff during that infinitesimal amount of time:

\footnotetext{
${ }^{10}$ We can show that if $2 \Pi_{3}>\Pi_{2}$, the no delay equilibrium is the unique SPE, but if this condition is not met there are multiple possible equilibria. We however point out that all of them yield relatively high profits for the innovator.

${ }^{11}$ Note that in Proposition 2, we focus on the symmetric MPE. There are however two degenerate, asymmetric pure strategy equilibrium in which imitator $l(j)$ never enters before $j(l)$ and where imitator $j(l)$ enters at date zero. Nonetheless, as an extensive previous literature that has been concerned with similar issues, (see, for instance, Bolton and Farrel (1990) and some of the references cited there), we believe that asymmetric pure strategy equilibria are both implausible and unsuitable to examine imitation in a decentralized market environment.

${ }^{12}$ This is a typical result in war of attrition games. War of Attrition games were first introduced by Maynard Smith (1974). See, for example, Fudenberg and Tirole (1991) for a formal definition of a war of attrition game and Hendricks et. al. (1988) for a full characterization. We note however that our setup is slightly more complex, since through his initial choice of the price of the first contract, the innovator controls the speed of the war of attrition.
} 
$r\left(\Pi_{3}-\kappa\right)$. The benefit of waiting is the avoided entry cost were his rival to enter first: $\lambda \kappa$. This tradeoff is reflected in the hazard rate given in result (ii): $\lambda=r\left(\Pi_{3}-\kappa\right) / \kappa$.

Proposition 2 demonstrates that, when trading knowledge is feasible, innovators enjoy monopoly profits for a random amount of time and the traditional view on the need for patent protection is overturned. We see that the extra reward received by the inventor when trading knowledge is considered is given by

$$
\begin{aligned}
& V_{s}-\Pi_{3}=\mu(\kappa)\left(\Pi_{1}-\Pi_{3}\right) \quad+\quad(1-\mu(\kappa)) \kappa \\
& \text { [Rewards from Delay] } \quad+\quad \text { [Revenues from Knowledge Sale] }
\end{aligned}
$$

The sources of rents come from both monopoly profits accumulated before entry of the first imitator and from contracting revenues at the entry date. We are of course mostly interested in the first source of rents.

We examine some comparative statics on these results. When $\kappa$ increases, the expected duration of monopoly time and the rents of the inventor increase. As $\kappa \rightarrow \Pi_{3}$, the cost of waiting goes to zero and, in the limit, entry never happens: $\mu(\kappa) \rightarrow 1$. So, due to the

possibility of trading knowledge, the inventor becomes a permanent monopolist. We note that this can be true for a very small imitation cost. If the imitation cost and triopoly profits are close and negligible, the innovator would obtain very small profits in the absence of knowledge trading but collects profits close to monopoly rents if contracting is possible. These results are summarized in the following Corollary:

Corollary 1 In the unique symmetric MPE: (i) The expected duration of monopoly time and the inventor's expected equilibrium payoff are strictly increasing in the imitation cost, $\kappa$; and: (ii) The inventor's expected equilibrium payoff converges monotonically to the present value of monopoly profits, $\Pi_{1}$, as $\kappa$ converges to $\Pi_{3}$.

\section{C On The Optimality of Transferable Contracts}

In Proposition 2 only transferable contracts were considered. This is restrictive since the inventor might prefer to sell knowledge through non-transferable contracts that prevent competition in the knowledge market. We show in this section that the inventor always strictly prefers to trade knowledge through transferable rather than non-transferable contracts.

We focus on MPE. In the case of non-transferrable contracts, competition in the market for knowledge occurs only when an imitator enters by copying. The unique MPE in this case is still the no-delay contracting equilibrium of Lemma 1. In the subgame that follows any history in which one of the imitators, say $j$, has bought knowledge at period $t$ through 
a non-transferable contract (what we call the bilateral monopoly subgame), there exists a unique SPE described below:

Lemma 2 In the unique SPE of the bilateral monopoly game that starts at period $t+1$, the inventor offers knowledge at a price $p_{s l}^{\tau}=\kappa$ for all periods $\tau \geq t+1$ and imitator $l$ buys it immediately at period $t+1$.

The inventor would like to promise the buyer to lower the price in the future to delay his entry into the market. This promise is, however, not credible as once that period comes, she has an incentive to keep the price high, and it is optimal for the buyer to accept such a high offer rather than to incur the imitation cost. Using the results of Proposition 2 and Lemma 3, we obtain our second main finding.

Proposition 3 In the unique MPE when non-transferable contracts are used: (i) Both imitators enter at period $t=0$ by buying knowledge at a price equal to $\kappa$; and: (ii) The inventor's equilibrium payoff $V_{s}^{\mathbf{n}}=\Pi_{3}+2 \kappa$ is strictly smaller than her equilibrium payoff $V_{s}$ when transferable contracts are used.

As in the case without contracting (Proposition 1), the imitators perceive that their entry cost will remain fixed through time and thus they decide to enter at period zero. However, in the present case, the entry cost remains constant over time due to the non-transferability clauses contained in the contracts. When using non-transferable contracts, the inventor cannot commit to lower the price of knowledge in the future and from the imitators'perspective, the game is as if knowledge could not be traded. The inventor, however, obtains higher rents: She appropriates, in the form of contracting revenues, what before were lost imitation costs.

Result (ii) shows however that the inventor always prefers to use transferable rather than non-transferable contracts. The intuition is as follows. Non-transferable contracts yield higher revenues (two contracts, instead of one, are sold at a price of $\kappa$ ) and, moreover, these revenues are received earlier (at period zero). However, the rents of the inventor are immediately reduced to triopoly profits. Transferable contracts, on the other hand, allow the inventor to commit to a lower future price of knowledge by introducing competition in the knowledge market. As a result, potential imitators delay their entry. Hence, Proposition 3 stresses that the extra profits due to the strategic delay in entry are larger than the lost contracting revenues.

It is important to understand this trade-off more formally. According to result (iii) of Proposition 2, the inventor's equilibrium reward is $V_{s}=\mu \Pi_{1}+(1-\mu)\left(\Pi_{3}+\kappa\right)$. Her equilibrium reward when non-transferable contracts are used is $V_{s}^{\mathbf{n}}=\Pi_{3}+2 \kappa$. Not forbidding 
resale is profitable if and only if $\mu\left(\Pi_{1}-\Pi_{3}\right)>(1+\mu) \kappa$. That is, the extra expected discounted amount of money collected during her monopoly time, $\mu\left(\Pi_{1}-\Pi_{3}\right)$, must be large enough to compensate her for the sum of: (i) The lost contracting revenues due to the fact that the second contract is sold for a zero price: $\kappa$; and: (ii) The lost contracting revenues due to the imitators' delay in purchasing: $\mu \kappa$.

But $\mu$ is determined by the equilibrium incentives of the imitators. In particular, the payoff corresponding to entering at any time in the support of their randomization must be equal to their expected payoffs if they follow the mixed strategies. So: $\Pi_{3}-\kappa=(1-\mu)\left(\Pi_{3}-\frac{\kappa}{2}\right)$, where the left hand side is the payoff from buying knowledge at time zero and the right hand side is the expected payoff from playing their corresponding mixed strategies. This equality implies that $(1+\mu) \kappa=2 \mu \Pi_{3}$, which in turns determine that transferability is optimal if and only if $\Pi_{1}>3 \Pi_{3}$, which is satisfied by Assumption $0 .{ }^{13}$

Some empirical evidence suggests the importance of imposing less restrictive clauses when patent protection is weak. Anand and Khanna (2000) report the percentage of nonexclusive licenses signed in their sample of contracts. ${ }^{14}$ For chemicals (mostly drugs in the sample), the percentage of non-exclusive licenses is $12.36 \%$, for computers $28.48 \%$ and for electronics $30.35 \%$. This evidence can be confronted to the data collected in the Carnegie Mellon Survey, reported by Cohen, Nelson and Walsh (2000), that asked managers about the effective mechanisms to appropriate returns from innovative activities. For drugs, 50\% of managers reported that patents were effective, for computers $41 \%$ and for electronics $21 \% .{ }^{15}$ So the sectors least likely to use patents are also those in which non-exclusive licenses are most prevalent. This evidence therefore suggests that contracts that impose less restrictive terms and don't prevent competition are beneficial for the inventor when patent protection is weak. This a priori surprising fact can be rationalized by our model. ${ }^{16}$

\section{D. Some Evidence}

In this section we provide suggestive evidence which reveals both the importance of knowledge trading and the potential relevance of the appropriation mechanism highlighted in this paper. In our theoretical exercise we underlined the existence of a natural and intuitive market force which generates innovative rents in the absence of patent protection. Finding empirical evidence of such forces is not an immediate exercise since patents are so prevalent

\footnotetext{
${ }^{13} \mathrm{An}$ alternative to non-transferrable contracts would be for the inventor to commit to a decreasing price schedule. The inventor would do weakly better. However, such commitments are not easy to put in place.

${ }^{14}$ See Table III (i) in their paper.

${ }^{15}$ See Table I in their paper.

${ }^{16}$ Admittedly, exclusive licenses are not strictly equivalent to our non-transferrable knowledge contracts but they are similar in the sense that they slow the speed at which prices decrease in the future.
} 
in many industrial sectors of developed countries. We show nevertheless that our mechanism might play an important role in countries where intellectual property protection is weak or non-existent.

We start by briefly discussing the evidence which suggests the existence of an active knowledge market. There appears to exist a robust market for technological know-how that does not involve patents (see Contractor (1985), Rostoker (1983) and Bessen, (2005)). According to the European Commission, pure know-how licensing agreements, that involve secret information, are playing an increasingly key role in the transfer of technology (Harris, (1997)). Moreover, as Gallini (2002) has also pointed out, components of technical knowhow absent from patent applications are often transferred through licensing contracts in high technology industries, such as software and biotechnology (See, also Arora, 2002).

To find more specific anecdotal evidence of the importance of our mechanism, it is natural to search for case studies in countries in which patent protection is weak or even non-existent. Until the recent TRIPS agreements, India did not grant product patents but process patents. This had important practical consequences, for instance, for the pharmaceutical sector: It meant that Indian generic producers could reverse engineer drugs from western big pharma companies and sell them in India as long as they used a slightly different process of production. Lanjow (1998) notes that the average delay between the date of world introduction by the inventor and the date of introduction in India is between 3 to 5 years. ${ }^{17}$ Although the author mentions that this unusually long delay might be due to regulatory deferrals, some circumstantial evidence suggests that a mechanism such as the one described in this paper could also be at play.

Consider the story of the compound oseltamivir (marketed by Roche as the famous Tamiflu). It was approved in the US in 1999. In October 2005, the Indian generic producer Cipla announced a plan to begin manufacture of generic oseltamivir without a license from Roche. ${ }^{18}$ In December 2005, presumably as a response, Roche granted a sub license to another Indian generic manufacturer, Hetero Drugs, for the production of osteltamivir. A similar pattern is observed for the production of HIV antiretroviral drugs in South Africa. In February 2001, Cipla announced plans to sell aids antiretroviral drugs to sub Saharan Africa and in September 2001 GSK, the patent owner, granted rights free of charge to Aspen, a local generic producer. In both cases, Hetero Drugs and Aspen obtained the knowledge at a smaller cost than Cipla and one reason for the delayed entry could be that, for some period of time, both generic producers preferred to wait, hoping that their rival would move first. ${ }^{19}$

\footnotetext{
${ }^{17}$ This data is obtained from a sample of 'blockbuster drugs' marketed in 1993.

${ }^{18}$ Even though this occurred after the TRIPS agreement was signed, the production of oseltamivir by Cipla was allowed by an Indian court that judged that the patent was not infringed.

${ }^{19}$ We point out that one feature of the model is not reflected in this example but does not matter for
} 
These examples and the data on delay presented in Lanjow (1998) correspond to wellknown successful drugs. However more examples of less popular drugs, or other inventions, may also exist. The difficulty is that these cases are not well documented. In general, we believe that our theoretical work opens the way for further empirical analysis and could provide a framework to conduct it.

\section{LARGE NUMBER OF IMITATORS}

In this section we extend the model of Section 3 to a large number of potential imitators, $\mathbf{N} \geq 2$. Consistently with the model of section 3 , we consider the case where $\Pi_{\mathbf{N}+1}>\kappa$. We show at the end of this section that this should be the relevant case when there are initial barriers to entry that limit the number of potential competitors. We obtain the following result:

Proposition 4 If $\Pi_{\mathbf{N}+1}>\kappa$, there is a MPE such that: (i) The optimal price of knowledge is $p_{\mathbf{N}}=\kappa$; (ii) The distribution of entry times of each imitator is exponential with hazard rate equal to $\lambda_{\mathbf{N}}=r\left(\Pi_{\mathbf{N}+1}-\kappa\right) /(\mathbf{N}-1) \kappa$; and (iii) The inventor's equilibrium payoff is $V_{s}=\mu_{\mathbf{N}} \Pi_{1}+\left(1-\mu_{\mathbf{N}}\right)\left[\kappa+\Pi_{\mathbf{N}+1}\right]$; where $\mu_{\mathbf{N}} \equiv r /\left[r+\mathbf{N} \lambda_{\mathbf{N}}\right]$.

This result generalizes the intuition of Proposition 2. After the first entry, the price of knowledge falls to zero, thus creating an incentive for all $N$ imitators to delay entry. We now examine how entry rates and profits of the innovator vary as $N$ increases:

Corollary 2 The MPE of Proposition 4 is such that: (i) The discounted length of monopoly profits $\mu_{\mathbf{N}}$ is increasing in $N$; (ii) For $\Pi_{\mathbf{N}+1}$ sufficiently close to $\kappa$, the innovator's profits $V_{s}$ are increasing in $N$ (iii) If $-\frac{\partial \Pi_{\mathrm{N}+1}}{\partial N}<\frac{\kappa}{N}$, the innovator's profits $V_{s}$ are increasing in $N$.

Corollary 2 shows that, surprisingly, an increase in the number of potential imitators can be beneficial for the innovator. Result (i) states that an increase in $N$ unambiguously increases the length during which the innovator can collect monopoly profits. As the number of imitators increase, if the entry rate of each imitator remained unchanged, entry of the first imitator would occur earlier $\left(\mu_{\mathbf{N}}\right.$ decreasing in $N$ when fixing $\left.\lambda_{N}\right)$. However, each potential imitator anticipates this and therefore decreases his entry rate in the hope of obtaining the knowledge for free. Overall result (i) shows that this second force dominates.

the results: The first imitator, Cipla, entered in both cases by imitating and not by contracting with the innovator. Note however that our model would yield exactly the same results if the innovator was assumed not to offer a contract before the entry of at least one imitator; the cost of entry would still fall from $\kappa$ (cost of imitating) to zero after the first entry due to competition on the market for knowledge. 
There are two effects of an increase in $N$ on the innovator's profits. The innovator collects monopoly profits for a longer period of time (result (i)), but when entry finally occurs, the profits he makes thereon, $\Pi_{\mathbf{N}+1}$, are decreased. Results (ii) and (iii) identify situations where the first effect dominates. The condition of result (ii) is that $\Pi_{\mathbf{N}+1}$ is close to $\kappa$. In this case, the discounted length of monopoly profits $\mu_{\mathbf{N}}$ is very large and the negative impact of $N$ on profits after entry of imitators becomes negligible. Result (iii) gives a different perspective: if post entry profits $\Pi_{\mathrm{N}+1}$ do not decrease too rapidly with $N$, the second effect is bounded and it guarantees that the innovator's profits are increasing in $N$.

These results therefore show that an increase in the number of imitators can have an unexpected effect on the innovator's profits. We conclude this section by providing a justification for our focus on the case $\Pi_{\mathbf{N}+1}>\kappa$. Consider a situation where imitators need to pay in period zero a very small base level entry cost to be in a position to imitate later on (invest in absorptive capacity or compelementary assets). If the number $N$ of imitators who pay the initial entry cost is such that $\Pi_{\mathbf{N}+1}<\kappa$, there always exists a SPE of the resulting game such that after entry of one innovator, the price of knowledge falls to zero and all imitators enter (Bertrand outcome as in the no-delay equilibrium of section 3). Anticipating this outcome, no imitator would find it profitable to be the first to imitate and incur the imitation cost $\kappa$, since the $N-1$ other imitators would follow suit, leading to negative profits $\left(\Pi_{\mathbf{N}+1}-\kappa<0 .{ }^{20}\right.$ Thus paying the initial small base entry cost would not be justified. In such a situation we would therefore expect the number $N$ of potential imitators to be such that $\Pi_{\mathbf{N}+1}>\kappa$, the case we study in this paper.

\section{Patents Vs SeCRECY}

Several influential surveys have systematically documented the fact that today, managers in most industries, rank patents below secrecy or the sale of complementary assets as a means of appropriating profits from their innovations. The Carnegie Mellon Survey, conducted in 1994 (Cohen et. al. 2000), shows that patents are ranked above secrecy in only two industries (special purpose machinery and medical equipments). However, this has not always been the case. The Yale Survey, conducted in 1983, reports that for both product and process innovations, secrecy was consistently ranked as one of the worst methods to protect an innovation. As Cohen et. al. (2000) point out, there is no apparent explanation for the 'growth in the importance of secrecy as an appropriability mechanism'. This fact is particularly surprising, since the period between 1983 and 1994 was one in which patent protection tended to strengthen.

\footnotetext{
${ }^{20}$ There are presumably other equilibria that could be the object of interesting future work but that are not the focus of the current paper.
} 
Number of industries ranking secrecy as:

\begin{tabular}{|c|c|c|c|c|}
\hline Mechanism & 1st & 2nd & 3rd & 4th \\
\hline Secrecy 1983 (process) & 2 & 10 & 19 & 2 \\
\hline Secrecy 1994 (process) & 21 & 10 & 1 & 1 \\
\hline Secrecy 1983 (product) & 0 & 0 & 11 & 22 \\
\hline Secrecy 1994 (product) & 13 & 11 & 2 & 5 \\
\hline
\end{tabular}

We show in this section that our model can help us understand both the choice between secrecy and patenting as well as the historical evolution of their relative importance. Consider a variant of the model where at date zero, the innovator, who faces $N$ imitators, can choose between secrecy and patenting. If the innovator chooses patenting, she incurs an initial cost $P$ (cost of filing) and obtains monopoly profits for a length of time $L$ after which all $N$ imitators can enter at no cost. The expected returns are given by:

$$
\begin{aligned}
V_{p} & =\int_{0}^{L} e^{-r t} \Pi_{1} d t+\int_{L}^{+\infty} e^{-r t} \Pi_{N+1} d t-P \\
& =\nu \Pi_{1}+(1-\nu) \Pi_{\mathbf{N}+1}-P \text { where } \nu=1-e^{-r L}
\end{aligned}
$$

If secrecy is chosen, we are in the context of the model of the previous sections. If knowledge cannot be traded, all imitators immediately enter and the innovator expects profits $\Pi_{\mathbf{N}+1}$. If knowledge can be traded, according to proposition 4, the expected returns from secrecy are given by:

$$
V_{s}=\mu_{\mathbf{N}} \Pi_{1}+\left(1-\mu_{\mathbf{N}}\right) \Pi_{\mathbf{N}+1}+\left(1-\mu_{\mathbf{N}}\right) \kappa
$$

We note that regardless of whether secrecy or patenting is chosen, the evolution of the innovator's profits is very similar: she enjoys a period of monopoly profits, followed by simultaneous entry of all imitators. The following result further characterizes the difference between these instruments:

Proposition 5 There exists $L_{1}^{*}>L_{2}^{*}>0$ such that, when knowledge can be traded, patents are preferred to secrecy if and only if $L>L_{1}^{*}$ and when it cannot be traded they are preferred if and only if $L>L_{2}^{*}$. Furthermore $L_{1}^{*}$ is increasing in $\kappa$ and in $N$ and decreasing in monopoly profits $\Pi_{1}$.

In the case where knowledge cannot be traded, secrecy is preferred to patenting only if the legal monopoly awarded by the patent is not sufficiently long to justify the cost $P$. On the contrary, in the case where knowledge can be traded, the patent needs to be much 
longer $\left(L>L_{1}^{*}>L_{2}^{*}\right)$ to become attractive. Indeed under secrecy, the innovator now enjoys monopoly profits for a random amount of time.

It is interesting to examine the comparative statics of the benchmark length $L_{1}^{*}$ (length in the case where knowledge can be traded). As intuition suggests, $L_{1}^{*}$ increases with the cost of imitation $\kappa$ : as imitation becomes more costly, the returns from secrecy increase and patents need to be longer if they are to be chosen. Interestingly, we show that $L_{1}^{*}$ also increases with $N$ : as the number of imitators increases, secrecy becomes more attractive. Both in the case of patenting and secrecy, there is a period where the innovator enjoys monopoly rents, of length $L$ in the case of patents and random in the case of secrecy. After this period, all $N$ imitators quasi simultaneously enter and profits fall to $\Pi_{N+1}$, profits that are decreasing in $N$ regardless of whether secrecy or patenting was chosen. However, while $N$ does not affect the legal monopoly of a patent, it increases $\mu_{\mathbf{N}}$, as was show in Corollary 2. Thus secrecy becomes relatively more attractive. Note that these comparative statics can provide testable implications on patenting rates in different industries.

We argue that the result of Proposition 5 allows us to explain the growth in the importance of secrecy between 1983 and 1994. Indeed we believe this was a period during which trading know how became more common. There is no systematic data on contracts to transfer knowledge or know-how in the absence of property rights. There is however extensive information about licensing markets. We believe that an increase in activity in one should be correlated with an increase in activity of the other. ${ }^{21}$ Licensing activity did indeed intensify in the period 1983 to 1994. Arora et.al. (2002) using data compiled by the Securities Data Company report that the total number of disclosed licensing deals during the period 1985 to 1989 was 1130 while for the years 1993 and 1994, 2009 and 2426 deals were signed respectively. ${ }^{22}$ If the increase in licensing activity is a good indicator of an increase in trading of knowledge, the previous result provides a convincing theoretical foundation for the surprising fact that secrecy rose in popularity as a means of appropriating rents: the minimum length needed to choose patents over secrecy moved from $L_{2}^{*}$ to the higher value $L_{1}^{*}$.

\section{KNOWLEDGE TRADING}

Our results clearly hinge on the feasibility of knowledge trades. Until this point, we have assumed that these transactions are frictionless. However, they might fail for at least two reasons.

\footnotetext{
${ }^{21}$ For instance Arora et. al. (2002) point out that licensing contracts, based on patents, often also include transfer of know how, such as sending teams to explain the technology to the buyer.

${ }^{22}$ The Securities Data Company contains data on licensing deals and joint ventures
} 
On the one hand, adverse selection is a typical feature of know-how transactions. Buyers might find difficult to determine their willingness to pay without knowing the relevant knowledge in the first place. But after buyers learn the know-how, they may have no incentives to compensate the seller (see Arrow (1962) and Anton and Yao (1994, 2002)). We however believe that this is not an important concern in the situation we consider since the innovator is already selling a product in the market whose value and success are publicly observed.

On the other hand, moral hazard problems undermine know-how transfers in many situations (Arora, Fosfuri and Gambardella (2001)). Since know-how transfers are usually costly and nonverifiable, sellers may be reluctant to deliver their know-how to the buyers. ${ }^{23}$ Thus buyers would like to make most of their payments after the know-how has been transferred. But after learning the know-how, they might refuse to make any payment to the sellers.

In this section we explore whether our results are robust to these moral hazard concerns. We find that a simple clause in the contract, which prescribes that the seller make a payment to an outside party if the buyer is forced to contract with someone else, implements knowhow transfers as previously suggested. We illustrate these ideas in the simplest possible principal-agent setting for the case of two potential imitators.

We introduce two contracting frictions in the model to address this question. First, transferring know-how imposes a cost of $c$ on the seller (for instance the cost of training personnel). Second, contracting imposes a small cost $\epsilon$ on the buyer (cost of writing up the contract). ${ }^{24}$ We assume that these costs are not too large: $c+\epsilon<\kappa<\Pi_{3} \cdot{ }^{25}$ Know-how transfers are 'observable but not verifiable.' In other words, the buyer observes the action taken by the seller but an outside party does not. Payments however between the buyer, the seller and third parties are both observable and verifiable.

We consider contracts that are a pair $\xi:=(p, f)$ where $p$ is, as before, a fix-fee to be paid up-front by the buyer and $f$ is a payment that needs to be made by the seller to a third party (a court for instance) if the buyer in later periods signs a contract with someone else to purchase knowledge.

We first consider the subgame where one imitator (say $j$ ) has already entered either by imitating or buying a transferrable contract. We show in the following result that there exists an equilibrium that overcomes the moral hazard problem: know how is transferred and payments are made.

Lemma 3 There exists a SPE such that (i) both sellers propose contracts $\xi:=(p, f)$, with

\footnotetext{
${ }^{23}$ As underlined by Arora, Fosfuri and Gambardella (2001) the transfer of know-how usually involves the training of personnel and the extent of technical services which is under the control of the seller.

${ }^{24}$ For the seller this small contracting cost is implicitly included in $c$

${ }^{25}$ If the various contracting costs are very large, our mechanism obviously does not work since it relies on contracting.
} 
$p=c$ and $f>c$; (ii) the remaining imitator signs with one of the sellers (iii) the chosen seller transfers the know how

The intuition for this result is the following: competition is intense between sellers and drives the price of knowledge to $p=c$, corresponding to the marginal cost of transferring knowledge. This payment is made up front by the buyer. In equilibrium, sellers of knowledge that signed a contract with $f>c$ do indeed transfer the knowledge. Suppose a seller deviates and does not transfer the know how. Then the buyer will sign a contract with a different seller. This is optimal for the buyer since he anticipates that the other seller will abide by the contract in equilibrium. The original seller will thus need to pay a fine $f>c$ and this deviation leaves him worse off. Contracts can thus be designed to generate a publicly observable signal indicating that knowledge has not been transferred by the original seller. ${ }^{26}$

This type of contracts rests on the existence of two potential sellers. Initially, when the innovator is the sole seller of knowledge, she thus cannot overcome the moral hazard problem and initial entry of the first imitator occurs, in this extension, not by contracting but by imitation, a feature that in fact appears quite realistic. We show however that this does not affect our result on delay:

Proposition 6 As $\Delta$ shrinks to zero, there exists a SPE such that:

(i) The first imitator enters by paying the imitation cost $\kappa$

(ii) The equilibrium distribution of entry times of each imitator converges to an exponential distribution with hazard rate equal to $\lambda=r\left(\Pi_{3}-\kappa\right) /(\kappa-c-\epsilon)$

(iii) The inventor's equilibrium expected payoff is $V_{s}=\mu(\kappa) \Pi_{1}+(1-\mu(\kappa)) \Pi_{3}$; where $\mu(\kappa):=r /(r+2 \lambda) \in(0,1)$.

This result generalizes the results in Proposition 2. We insist on two minor differences. First, the hazard rate of the exponential distribution of entry times is slightly modified. Indeed, the price of knowledge drops to $c$, not to zero, since the seller needs to be compensated for his transfer cost. Furthermore, the buyer needs to pay the small contracting cost $\epsilon$. Nevertheless the second imitator is still in a better position than the first since he pays a lower price for knowledge $(c+\epsilon<\kappa)$. The second difference is that the innovator does

\footnotetext{
${ }^{26}$ Note that this is not the unique type of equilibrium. There is also an equilibrium based on different expectations, where no contract is signed and sellers never transfer the knowledge. A variant on the contracts we presented can overcome this problem. Suppose that the fine $f$ is paid to future sellers of knowledge but needs to be reimbursed if yet another contract is signed. Say there are two sellers $i$ and $j$, and $i$ signs the initial contract. If the buyer then signs with $j, i$ needs to pay $f$ to $j$, a fee that needs to be reimbursed if the buyer subsequently signs with someone else. This would eliminate the no contracting equilibrium but could introduce problems of collusion between the buyers and later sellers. The purpose of this section is to illustrate solutions to the moral hazard problem, but a complete analysis is outside the scope of the current paper.
} 
not collect any profits from selling contracts: the first entry occurs through imitation and subsequently, competition drives the price of knowledge to its marginal value.

We have shown that certain contractual features can be used to overcome the moral hazard problem inherent in know how transfers. We note that, although we focused on one particular solution, other authors, most notably Arora, Fosfuri and Gambardella (2001), have discussed various other means by which the moral hazard problem could be overcome. They insist on the fact that know-how can be bundled with complementary inputs, in particular patents, to achieve efficient transfers. Their main insight is that, by using a sequential mechanism, the complementary can be exploited to create a situation of mutual 'hostage taking' (between the buyer and the seller) that allows a self-enforcing contract to work. In the context we consider, patents can of course not be used, but we could imagine bundling know how transfers with, for instance, the sale of machinery in the possession of the seller. ${ }^{27}$

\section{Concluding Remarks}

The main goal of this paper was to study natural market forces that protect rents of innovators faced with easy imitation. We show that the introduction of a market for knowledge fundamentally affects the traditional view on the need for patent protection. Even in the absence of such protection, imitators strategically delay their entry and the inventor accumulates monopoly profits for a random time period. In essence, we have shown that potential knowledge trades between inventors and imitators serve as good substitutes for patents in terms of guaranteeing rents for the inventor.

To examine the appropriability problem in the presence of knowledge trading and revisit the conventional wisdom on intellectual property rights, we built the simplest possible model. We made abstraction of certain issues and we mention two of those. First, we assumed that the imitation cost is commonly known. It would be interesting to presume that imitators have private information about their imitation costs and to examine how this affects the inventor's equilibrium payoff. Second, our model does not consider the possibility of sequential invention. Contracting in that case might provide not only knowledge to reproduce the current innovation but also to discover future improvements. This could be the object of interesting future work.

\section{APPENDIX}

Proof of Proposition 1. A pure strategy for imitator $g$ prescribes, at each $t$, whether to imitate $i_{g}$ or to wait $w_{g}$. Consider the decision problem following a history in which only one

\footnotetext{
${ }^{27}$ Finally note that Arora, Fosfuri and Gambardella (2001) also mention two other solutions: (i) contracts involving royalties and (ii) reputation building in the context of a repeated game. This could also be part of a solution in the context we consider.
} 
imitator, say $l$, has imitated at period $t-1$. Then it is obvious that $j$ 's unique best response is to imitate at $t$. We now turn our attention to those histories starting at $t$ and in which no imitator has imitated yet. Given the symmetry of the game, we study $j$ 's best response to the following two strategies of $l$. First, suppose that $l$ 's strategy is $i_{l}$ at $t$. Then it is obvious that $j$ 's unique best response is $i_{j}$ at $t$. Second, suppose that l's strategy dictates to wait until $t_{l}>t$. Then: $j$ 's unique best response is also $i_{j}$ at $t$. Indeed, recall that we showed that if $j$ imitates at $t_{j}<t_{l}, l$ 's best response is to imitate at $t_{j}+1$. Thus, if $j$ chooses $i_{j}$ at $t_{j}$ such that: $t \leq t_{j}<t_{l}$ he obtains a payoff in period $t$ of $V_{j}(t)=\delta^{\left(t_{j}-t\right)}\left[(1-\delta) \Pi_{2}+\delta \Pi_{3}-\kappa\right]$. But if he chooses $i_{j}$ at $t_{j} \geq t_{l}$ he receives a payoff in period $t$ of $V_{j}(t)=\delta^{\left(t_{j}-t\right)}\left[\Pi_{3}-\kappa\right]$. Comparing these payoffs, it follows that $j$ 's unique best response is to imitate at $t$.

So, this analysis reveals that there is a unique SPE in which the imitators choose to imitate immediately at all periods in which imitation has not occurred yet. Thus, the unique equilibrium outcome is both imitators choosing to imitate at period zero and the equilibrium payoff for the inventor and the imitators are $\Pi_{3}$ and $\Pi_{3}-\kappa$ respectively.

Proof of Lemma 1. A (Markovian) strategy for the sellers ( $j$ and $s$ ) specifies a price at which they offer knowledge through a contract if $l$ has not entered yet. Imitator $l$ 's decision rule dictates whether to enter or not and how to enter as a function of the prices. We follow a sequence of steps. In step 1, we show that the unique pair of stationary prices that can be part of an equilibrium is $p_{s l}=p_{j l}=0$ as claimed in Lemma 1. In step 2, we show that the buyer has also a unique best response and thus that the no-delay contracting equilibrium is the unique MPE.

STEP 1. First: $l$ will enter for sure since entry by imitation is always profitable. Second: Entry will occur by contracting. Suppose it were not the case. Then one of the sellers $(j$ or $s$ ) might deviate, at the time of entry, and offer a contract at a price equal to $\kappa$ that would be accepted by $l$. This deviation is payoff profitable since: (i) It strictly increases the contracting revenues of the seller; and: (ii) It does not affect the present value of the market profits of the deviant seller as entry would have taken place at that period anyway. Thus we can rule out as equilibrium candidates any pair of stationary prices above $\kappa$. Furthermore, any pair of stationary prices at which one or both sellers get positive contracting revenues is not immune to a profitable deviation. At least one of them might decrease his/her price and increase his/her contracting revenues without affecting the present value of his/her market profits; and: (iii) Any pair of stationary prices at which one seller sets a zero price and the other a positive price is not resistant to a profitable deviation by the lowest price seller. Indeed, he or she can find a higher price to increase his or her contracting revenue without affecting his or her market profits. Thus the unique pair of stationary prices that can be part of an equilibrium is $p_{s l}=p_{j l}=0$ (Bertrand outcome). 
STEP 2. We show that the equilibrium strategy of the buyer is unique. Say that $l$ observes a pair of prices $\left\{p_{s l}, p_{j l}\right\}$ different from $p_{s l}=p_{j l}=0$. Let $m \equiv j, s$ denote the seller who offers the minimal price and $p_{m} \equiv \min _{m \in\{j, s\}} p_{m l}$. His unique best response is: contract $c_{l m}$ if $p_{m} \leq \min \left[\kappa,(1-\delta) \Pi_{3}\right]$; imitate $i_{l}$ if $\kappa \leq \min \left[p_{m},(1-\delta) \Pi_{3}\right]$; and wait $w_{l}$ if $\min \left[p_{m}, \kappa\right]>(1-\delta) \Pi_{3}$. These strategies follow naturally from the fact that by waiting one period, the imitator can get the contract at a zero price next period but abandons triopoly profits during the current period. Hence, the buyer's decision rule and the price offers at any period $p_{s l}=p_{j l}=0$ constitute the unique MPE.

\section{Proof of Proposition 2.}

STEP 1. The inventor offers to sell two contracts at a price $p_{s g} \leq \kappa$

A (Markovian) contracting strategy specifies a time-independent pair of prices $p_{s g} \in$ $[0, \infty]$ for $g \in\{j, l\}$ if entry has not happened yet. In this first step we show that an optimal contracting strategy must be inclusive: Two knowledge contracts must be offered at prices $p_{s g} \leq \kappa$ for $g \in\{j, l\}$. We prove this by showing that for any (Markovian) contracting strategy which excludes an imitator there exists an inclusive contracting strategy that performs better for the inventor.

Consider, first, a strategy which excludes both imitators: Prices are $p_{s g}=\infty$ for $g \in$ $\{j, l\}$. Then, the inventor prefers the contracting strategy in which two contracts are offered at $p_{s g}=\kappa$ for $g \in\{j, l\}$. To see this, observe that:

1. For the imitators both strategies are payoff equivalent since: (i) Their mode of entry, contracting or imitating, does not affect the profits that they collect in the market; (ii) Under both strategies, their entry cost is equal to $\kappa$ if they enter first; and: (iii) The price of knowledge for the second contract will be equal to zero since competition is assured after the first entry.

2. The inventor, however, prefers the second (inclusive) contracting strategy since: (i) The entry times of the imitators have not been affected and so the present value of her market profits are the same under both contracting strategies; and: (ii) When entry happens, it takes places through contracting and the inventor receives strictly positive contracting revenues.

It follows that the same type of argument applies to show that there exists an inclusive strategy that the inventor prefers to a contracting strategy which excludes only one of the imitators.

Step 2. We focus on a symmetric Markov Perfect Equilibrium. We consider directly the continuous time limit of our model. ${ }^{28}$ We denote by $G_{g}(t):[0, \infty) \times[0, \kappa] \rightarrow[0,1]$ the distribution function of entry times for imitator $g$. We assume momentarily that $G_{g}(t)$ has a

\footnotetext{
${ }^{28}$ Fudenberg and Tirole (1991) show that taking the limit of the discrete time game is equivalent to solving the continuous time game.
} 
density denoted by $g_{g}(t)$. In a mixed strategy equilibrium, if the first sale of knowledge has not happened up to time $t$, the buyers must be indifferent between: (i) Buying knowledge at $t$; and (ii) Waiting $d t$ extra units of time to buy knowledge at price $p_{s g}$. This indifference condition requires that the opportunity cost of waiting $d t$ extra units of time $(M C)$ be exactly equal to the expected marginal benefit of waiting $d t$ extra units of time $(E M B)$.

The $M C$ is the flow of profits that an imitator obtains if he is the leader at time $t$. Using Step 1 we have that $M C=r\left[\Pi_{3}-p_{s g}\right] d t$. The MB is the increase in the payoff that an imitator receives if he is one of the followers rather than the leader. That is $M B=p_{s g}$. But an imitator receives this benefit iff the other imitator $g^{\prime}$ enters first which occurs with hazard rate $\lambda_{g^{\prime}}$.

In equilibrium: $E M B=M C$, implying that the distribution of equilibrium entry times is characterized by a constant hazard rate. Consider player $l$, this hazard rate is determined by the fact that player $j$ is indifferent between entering and waiting

$$
\lambda_{l}=\frac{r\left(\Pi_{3}-p_{s j}\right)}{p_{s j}}
$$

A distribution has a constant hazard rate iff it is an exponential distribution. Thus, the cumulative distribution function (cdf) of entry times for $l$ is $G_{l}(t)=1-e^{-t \lambda_{l}}$ for $t \in[0, \infty)$.

STEP 3. Using step 2 we can calculate the expected profits of the inventor if he chooses $p \equiv\left(p_{s j}, p_{s l}\right)$. Her payoff depends on the time of the first sale, $t_{1} \equiv \min \left\{t_{j}, t_{l}\right\}$, a random variable that takes values in $[0, \infty)$. Since $t_{j}$ and $t_{l}$ are independent $\mathrm{rv}$ with hazard rates $\lambda_{j}$ and $\lambda_{l}, t_{1}$ has a hazard rate equal to $\lambda_{j}+\lambda_{l}$. As the second imitator enters almost instantaneously at time $t_{1}, s$ obtains: (i) A flow of $\pi_{1}$ up to time $t_{1}$; (ii) A flow of $\pi_{3}$ from time $t_{1}$ on; and (iii) At time $t_{1}$, she receives either $p_{s j}$ or $p_{s l}$ depending on the identity of the first imitator. Overall, the inventor's expected payoff is given by:

$$
V_{s}(p)=\frac{r \Pi_{1}}{\left(r+\lambda_{j}+\lambda_{l}\right)}+\frac{\left(\lambda_{j}+\lambda_{l}\right) \Pi_{3}}{\left(r+\lambda_{j}+\lambda_{l}\right)}+\frac{\lambda_{j} p_{s j}+\lambda_{l} p_{s l}}{\left(r+\lambda_{j}+\lambda_{l}\right)}
$$

STEP 4. The payoff maximizing knowledge prices are $p_{s j}^{*}=p_{s l}^{*}=\kappa$.

The inventor must choose a pair $\left\{p_{s j}, p_{s l}\right\}$ to maximize $V_{s}(p)$. The derivative of $V_{s}(p)$ with respect to $p_{s j}$ is:

$$
\frac{\partial V_{s}}{\partial p_{s j}} \equiv V_{s}^{j}=\frac{\lambda_{j}}{D}-\frac{1}{D^{2}} \frac{\partial \lambda_{l}}{\partial p_{s j}}\left[\pi_{1}-\pi_{3}-p_{s l} r-p_{s l} \lambda_{j}+\lambda_{j} p_{s j}\right]
$$

where $D \equiv\left(r+\lambda_{j}+\lambda_{l}\right)$. Using, from step 2 , the result for $\lambda_{j}$, we obtain: $V_{s}^{j}=\frac{\lambda_{j}}{D}-$ $\frac{1}{D^{2}} \frac{\partial \lambda_{l}}{\partial p_{s j}}\left[\pi_{1}-2 \pi_{3}+\lambda_{j} p_{s j}\right]$. Since $\partial \lambda_{l} / \partial p_{s j}<0$ and $\pi_{1}>2 \pi_{3}$, it follows that $V_{s}^{j}$ is strictly 
increasing in $p_{s j}$ for all $p_{s l}>0$. By symmetry, $V_{s}^{l}$ is strictly increasing in $p_{s l}$ for all $p_{s j}>0$. So, $p_{s j}^{*}=p_{s l}^{*}=\kappa$.

To conclude: Result(i) is a direct consequence of step 4; Result (ii) is step 2 for the optimal contract prices $p_{s j}^{*}=p_{s l}^{*}=\kappa$; and finally Result (iii) is step 3 for $p_{s j}^{*}=p_{s l}^{*}=\kappa$.

Proof of Lemma 2. The strategy for the inventor dictates the price of knowledge at the beginning of each period $\tau \geq t+1$ for every feasible history (i.e., any history for which $l$ has not entered yet), $p_{s l}^{\tau}: H^{\tau} \rightarrow[0, \infty]$. The strategy of $l$ dictates, at each period $\tau \geq t+1$, whether to enter or not and how to enter, $d_{l}^{\tau}: H^{\tau} \times[0, \infty] \rightarrow\left\{i_{l}, c_{l}, w_{l}\right\}$. Any SPE in pure strategies must satisfy the following two properties:

P1 (Imitation never occurs). Imitator $l$ enters the market by buying knowledge.

Suppose not and that he were to imitate at period $\tau \geq t+1$. Then the inventor would be strictly better off by selling a contract at any price that imitator $l$ would accept. This implies that the inventor will never offer a contract at a price strictly higher than $\kappa$.

P2 (No Delay). Imitator $l$ buys a contract immediately when it is offered if its price is equal or smaller than $\kappa$.

By P1 $l$ never imitates in equilibrium. When a contract is offered at period $\tau$ at a price smaller or equal than $\kappa$ he can either accept it or reject it and wait to accept a future offer. Rejecting a current offer is a best response only if $l$ expects to obtain a higher payoff by accepting a future offer. However this is clearly impossible: At any time period at which the contract is sold, its price must be equal to $\kappa$. Otherwise $s$ could increase its price and be strictly better off. $\square$

Proof of Proposition 3. A pure strategy for the inventor prescribes to offer, at the beginning of each period for which no imitator has entered yet, a pair of knowledge prices. (Only non-transferable contracts are offered). For all $t=0,1, \ldots \sigma^{t}: H^{t} \rightarrow[0, \infty] \times[0, \infty]$. For the imitators, the strategy is a sequence of functions $\left\{e_{g}^{t}\right\}_{t=0}^{\infty}$ for $g \in\{j, l\}$ such that $e_{g}^{t}: H^{t} \times[0, \infty] \times[0, \infty] \rightarrow\left\{i_{g}, c_{g}, w_{g}\right\}$

STEP 1. Any SPE must satisfy the following three properties:

$\mathbf{P 1}$ (Imitation never occurs). The imitators enter the market by buying knowledge.

The argument is the same as that of Lemma 2 but with an additional subtlety. Consider an imitator who deviates and enters by imitating. Competition in the knowledge market follows and the no-delay contracting equilibrium of Lemma 1 is the unique equilibrium. Thus, the imitator who deviates makes zero profit in the knowledge market. Hence, for any offer such that the fee is less or equal than $\kappa$, imitators must enter by buying knowledge.

P2 (Simultaneous Entry). The imitators enter the market at the same time period.

Suppose it were not the case. Then one of them, say $j$, would enter at period $\tau \geq t$ and $l$ at period $\widehat{\tau}>\tau$. By Lemma 3, in equilibrium, $\widehat{\tau}=\tau+1$ and $l$ 's equilibrium payoff, in 
period $\tau$ units, would be $\delta\left(\Pi_{3}-\kappa\right)$. However, by deviating and buying knowledge at period $\tau$, l's worst payoff would be $\left(\Pi_{3}-\kappa\right)$ which is strictly higher than $\delta\left(\Pi_{3}-\kappa\right)$.

P3 (No Delay). Whenever the innovator offers contracts at prices smaller or equal than $\kappa$, the offers will be simultaneously accepted by the imitators.

By P1 and P2, in equilibrium, imitation never takes place and entry occurs simultaneously. Rejecting any current offer for a price equal or smaller than $\kappa$ cannot be part of an equilibrium. The reason is that by rejecting current offers, the imitators postpone their entry and sacrifice current profits. But then the best offer they can expect from the inventor in the next period is a contract for a price of $\kappa$. Otherwise, the inventor could increase her price and be strictly better off.

P1, P2 and P3 together imply that, at any time period and for any history at which entry has not happened yet, the imitators will simultaneously and immediately accept to buy a contract at a price equal or smaller than $\kappa$ and they will imitate iff the posted price is higher than $\kappa$. The unique best response of the inventor is to offer, at any time period and for any history at which a contract has not been bought yet, a pair of contracts at prices equal to $\kappa$. So, in the unique MPE, both imitators enter at period zero and the inventor's equilibrium payoff is $\Pi_{3}+2 \kappa$.

STEP 2. In the case of non-transferable contracts the inventor's payoff is $V_{s}^{\mathbf{n}}=\Pi_{3}+2 \kappa$. In the case of transferable contracts her payoff is $V_{s}=\frac{\pi_{1}}{r+2 \lambda}+\frac{2 \lambda}{r+2 \lambda}\left(\Pi_{3}+\kappa\right)$. Let $V \equiv V_{s}-V_{s}^{\mathbf{n}}$. Then $V>0$ iff: $\Pi_{1}-\Pi_{3}>2 \kappa(r+\lambda)$. Using the expression for $\lambda$ from Proposition 2 we find: $V>0$ iff $\Pi_{1}-3 \Pi_{3}>0$. This last inequality is satisfied by Assumption 0 .

Proof of Proposition 4. We prove this proposition in a number of steps. After entry of any number of imitators, we concentrate on the MPE such that all active players sell knowledge at a zero price to every inactive imitator. In such an equilibrium, after $n \in \mathbf{N}$ imitators enter the market, $\mathbf{N}-n$ contracts are sold instantaneously at a zero price to the remaining $\mathbf{N}-n$ imitators. Here, we concentrate on the monopoly subgame.

STEP 1. The inventor offers to sell $\mathbf{N}$ contracts at a price $p_{s \mathbf{N}} \leq \kappa$

This step is a generalization of step 1 of Proposition 2. It follows the same argument: No imitator enters by imitating as the inventor would weakly increase his payoff by offering a contract to that imitator at a price equal to the imitation cost $\kappa$. The implication of this step is that the leader imitator receives an instantaneous payoff in time $t$ equal to $V_{1}=\Pi_{\mathbf{N}+1}-p_{s \mathbf{N}}$.

Step 2. We focus on a symmetric Markov Perfect Equilibrium. Using Step 1, we denote by $G_{\mathbf{N}}\left(t, p_{s \mathbf{N}}\right):[0, \infty) \times[0, \kappa] \rightarrow[0,1]$ the distribution function of entry times for the imitators, with density denoted by $g_{\mathbf{N}}\left(t, p_{s \mathbf{N}}\right)$. As in Proposition 2 , in a mixed strategy equilibrium, the opportunity cost of waiting $d t$ extra units of time $(M C)$ be exactly equal 
to the expected marginal benefit of waiting $d t$ extra units of time $(E M B)$.

The $M C$ is the flow of profits that an imitator obtains if he is the leader at time $t$. Using Step 1 we have that $M C=r V_{1} d t$. The MB is the increase in the payoff that an imitator receives if he is one of the followers rather than the leader. That is $M B=p_{s \mathbf{N}}$. But an imitator receives $p_{s \mathbf{N}}$ iff at least one of the other $\mathbf{N}-1$ imitators enters first. Since: (i) We focus on a symmetric equilibrium and: (ii) Randomizations by the imitators are independent; it follows that: $E M B=(\mathbf{N}-1) \lambda_{\mathbf{N}}\left(t, p_{s \mathbf{N}}\right) p_{s \mathbf{N}}$ where $\lambda_{\mathbf{N}}\left(t, p_{s \mathbf{N}}\right)$, the hazard rate, is defined as: $\lim _{\Delta \downarrow 0} \operatorname{Pr}\left(t<t_{g} \leq t+\Delta \mid t_{g} \geq t\right) / \Delta=g\left(t, p_{s \mathbf{N}}\right) /\left(1-G\left(t, p_{s \mathbf{N}}\right)\right)$.

In equilibrium: $E M B=(\mathbf{N}-1) \lambda_{\mathbf{N}}\left(t, p_{s \mathbf{N}}\right)\left(V_{2}-V_{1}\right)=r V_{1} d t=M C$, implying that the distribution of equilibrium entry times is characterized by a constant hazard rate given by

$$
\lambda_{\mathbf{N}}\left(p_{s \mathbf{N}}\right) \equiv \lambda_{\mathbf{N}}=\frac{r V_{1}}{(\mathbf{N}-1)\left(V_{2}-V_{1}\right)}=\frac{r\left(\Pi_{\mathbf{N}+1}-p_{s \mathbf{N}}\right)}{(\mathbf{N}-1) p_{s \mathbf{N}}}
$$

And the cdf for the imitators is $G\left(p_{s \mathbf{N}}\right)=1-e^{-\lambda_{\mathbf{N}}\left(p_{s \mathbf{N}}\right) t}: t \in[0, \infty)$

SteP 3. We establish that $p_{s \mathbf{N}}^{*}=\kappa$.

If we follow the same logic as in Proposition 2, step 3, since the time of the first entry $t_{1}:=$ $\min \left\{t_{i}, t_{j}, \ldots t_{\mathbf{N}}\right\}$ has an exponential distribution with parameter equal to $\mathbf{N} \lambda_{\mathbf{N}}$, it follows that the innovator's expected payoff is $V_{s \mathbf{N}}\left(p_{s \mathbf{N}}\right)=\mu\left(\lambda_{\mathbf{N}}\right) \Pi_{1}+\left(1-\mu\left(\lambda_{\mathbf{N}}\right)\right)\left[p_{s \mathbf{N}}+\Pi_{\mathbf{N}+1}\right]$; where $\mu\left(\lambda_{\mathbf{N}}\right):=r /\left[r+\mathbf{N} \lambda_{\mathbf{N}}\right]$. Then: $\partial V_{s \mathbf{N}}\left(p_{s \mathbf{N}}\right) / \partial p_{s \mathbf{N}}=\left(\partial \lambda_{\mathbf{N}} / \partial p_{s \mathbf{N}}\right)\left(r \mathbf{N} / D^{2}\right)\left(p_{s \mathbf{N}}+\Pi_{\mathbf{N}+1}-\Pi_{1}\right)+$ $\left(\mathbf{N} \lambda_{\mathbf{N}} / D\right)$; where $D \equiv\left(r+\mathbf{N} \lambda_{\mathbf{N}}\right)$. Since we consider the case $\Pi_{\mathbf{N}+1}>\kappa$ and $p_{s \mathbf{N}} \leq \kappa$, we have $\sup _{p_{s \mathbf{N}}}\left(p_{s \mathbf{N}}+\Pi_{\mathbf{N}+1}-\Pi_{1}\right)<2 \Pi_{\mathbf{N}+1}-\Pi_{1}<0$ by Assumption 0. Last $\partial \lambda_{\mathbf{N}} / \partial p_{s \mathbf{N}}<0$ ensues that $\partial V_{s \mathbf{N}}\left(p_{s \mathbf{N}}\right) / \partial p_{s \mathbf{N}}>0$ for all $p_{s \mathbf{N}} \in(0, \kappa]$ and so $p_{s \mathbf{N}}^{*}=\kappa$ as stated.

It follows directly that

$$
\lambda_{\mathbf{N}}=\frac{r V_{1}}{(\mathbf{N}-1)\left(V_{2}-V_{1}\right)}=\frac{r\left(\Pi_{\mathbf{N}+1}-\kappa\right)}{(\mathbf{N}-1) \kappa}
$$

and that: $V_{\mathbf{N}}=\mu_{\mathbf{N}} \Pi_{1}+\left(1-\mu_{\mathbf{N}}\right)\left[\kappa+\Pi_{\mathbf{N}+1}\right]$ for $\mu_{\mathbf{N}} \equiv r /\left[r+\mathbf{N} \lambda_{\mathbf{N}}\right]$.

Proof of Corollary 2. We have $\mu_{N}=\frac{(N-1) \kappa}{N \Pi_{N+1}-\kappa}$. Result (i) is an immediate consequence:

$$
\frac{\partial \mu_{N}}{\partial N}=\frac{1}{\left(N \Pi_{N+1}-\kappa\right)^{2}}\left[\kappa\left(\Pi_{N+1}-\kappa\right)-N \frac{\partial \Pi_{N+1}}{\partial N}(N-1) \kappa\right]>0
$$

The innovator's profits vary with $N$ in the following way:

$$
\begin{aligned}
\frac{\partial V_{s}}{\partial N} & =\frac{1}{\left(N \Pi_{N+1}-\kappa\right)^{2}}\left[\kappa\left(\Pi_{N+1}-\kappa\right)\left(\Pi_{1}-\Pi_{N+1}-\kappa\right)\right. \\
& \left.+\frac{\partial \Pi_{N+1}}{\partial N}\left(-N(N-1) \kappa+N\left(\Pi_{N+1}-\kappa\right)\left(N \Pi_{N+1}-\kappa\right)\right)\right]
\end{aligned}
$$


Result (ii) is obtained since when $\Pi_{N+1} \simeq \kappa$, then

$$
\frac{\partial V_{s}}{\partial N} \simeq \frac{1}{\left(N \Pi_{N+1}-\kappa\right)^{2}}\left[\kappa\left(\Pi_{N+1}-\kappa\right)\left(\Pi_{1}-\Pi_{N+1}-\kappa\right)-N(N-1) \kappa \frac{\partial \Pi_{N+1}}{\partial N}\right]>0
$$

Finally, from the expression for $\frac{\partial V_{s}}{\partial N}$ we obtain directly the sufficient condition expressed in result (iii), using the fact that $\Pi_{1}-\Pi_{N+1}-\kappa>N \Pi_{N+1}-\kappa\left(\right.$ as $\left.\Pi_{1}>(N+1) \Pi_{N+1}\right)$.

\section{Proof of Proposition 5.}

The difference in payoffs between secrecy and patenting, when knowledge cannot be traded, is given by: $V_{s}-V_{p}=-\left(1-e^{-r L}\right)\left(\Pi_{1}-\Pi_{N+1}\right)+P$. This difference is decreasing in $L$ and there therefore exists $L_{2}^{*}$ such that patents are chosen if and only if $L>L_{2}^{*}$. $L_{2}^{*}$ :

$$
L_{2}^{*}=-\frac{1}{r}\left[\ln \left(\Pi_{1}-\Pi_{N+1}-P\right)-\ln \left(\Pi_{1}-\Pi_{N+1}\right)\right]
$$

When knowledge can be traded, the difference in payoffs between secrecy and patenting is given by: $V_{s}-V_{p}=\left(\mu_{\mathbf{N}}-\left(1-e^{-r L}\right)\right)\left(\Pi_{1}-\Pi_{N+1}\right)+\left(1-\mu_{\mathbf{N}}\right) \kappa+P$. This difference is decreasing in $L$ and there therefore exists $L_{1}^{*}$ such that patents are chosen if and only if $L>L_{1}^{*}$ :

$$
L_{1}^{*}=-\frac{1}{r}\left[\ln \left(\left(1-\mu_{\mathbf{N}}\right)\left(\Pi_{1}-\Pi_{N+1}-\kappa\right)-P\right)-\ln \left(\Pi_{1}-\Pi_{N+1}\right)\right]
$$

We see that $L_{1}^{*}-L_{2}^{*}>0$ We now examine the comparative statics. To simplify the derivations, we establish these comparative statics in the case where $P=0$ :

$$
\begin{array}{r}
\frac{\partial L_{1}^{*}}{\partial \Pi_{1}}=\frac{1}{r}\left[\frac{1}{\Pi_{1}-\Pi_{N+1}}-\frac{1}{\Pi_{1}-\Pi_{N+1}-\kappa}\right]<0 \\
\frac{\partial L_{1}^{*}}{\partial \kappa}=\frac{1}{r}\left[\frac{\partial \mu_{\mathbf{N}} / \partial \kappa}{1-\mu_{\mathbf{N}}}+\frac{1}{\Pi_{1}-\Pi_{N+1}-\kappa}\right]>0
\end{array}
$$

We now examine the comparative statics with respect to $N$ :

$$
\begin{aligned}
\frac{\partial L_{1}^{*}}{\partial N} & =\frac{1}{r} \frac{\partial \mu_{\mathbf{N}} / \partial N}{1-\mu_{\mathbf{N}}}+\frac{1}{r} \frac{\partial \Pi_{N+1}}{\partial N}\left[\frac{1}{\Pi_{1}-\Pi_{N+1}-\kappa}-\frac{1}{\Pi_{1}-\Pi_{N+1}}\right] \\
& =\frac{1}{r} \frac{1}{1-\mu_{\mathbf{N}}} \frac{\kappa\left(\Pi_{N+1}-\kappa\right)}{\left(N \Pi_{N+1}-\kappa\right)^{2}} \\
& -\frac{1}{r} \frac{\partial \Pi_{N+1}}{\partial N}\left[\frac{(N-1) \kappa}{\left(\Pi_{N+1}-\kappa\right)} \frac{1}{\left(N \Pi_{N+1}-\kappa\right)}+\frac{1}{\Pi_{1}-\Pi_{N+1}}-\frac{1}{\Pi_{1}-\Pi_{N+1}-\kappa}\right]
\end{aligned}
$$

The first term is positive since $\Pi_{N+1}>\kappa$. We will show that the second term is positive, 
and since $\frac{\partial \Pi_{N+1}}{\partial N}<0$, this is equivalent to

$$
\begin{aligned}
& \frac{(N-1) \kappa}{\left(\Pi_{N+1}-\kappa\right)} \frac{1}{\left(N \Pi_{N+1}-\kappa\right)}+\frac{1}{\Pi_{1}-\Pi_{N+1}}-\frac{1}{\Pi_{1}-\Pi_{N+1}-\kappa}>0 \\
\Leftrightarrow & \frac{(N-1) \kappa}{\left(\Pi_{N+1}-\kappa\right)\left(N \Pi_{N+1}-\kappa\right)}>\frac{\kappa}{\left(\Pi_{1}-\Pi_{N+1}\right)\left(\Pi_{1}-\Pi_{N+1}-\kappa\right)} \\
\Leftrightarrow & (N-1) \Pi_{1}\left[\Pi_{1}-2 \Pi_{N+1}-\kappa\right]+\Pi_{N+1}\left[-\Pi_{N+1}+2 N \kappa\right]-\kappa^{2}>0
\end{aligned}
$$

Using the fact that $\Pi_{1}>\Pi_{N+1}$, a sufficient condition is $\Pi_{1}\left[(N-1) \Pi_{1}-(2 N-3) \Pi_{N+1}+N \kappa\right]>$ 0 . Given that $\Pi_{1}>\frac{(2 N-3)}{(N-1)} \Pi_{N+1}$, for all $N \geq 2$, we have shown the result: $\frac{\partial L_{1}^{*}}{\partial N}>0$.

\section{REFERENCES}

Anand, Bharat and Tarun Khanna. 2000. "The Structure of Licensing Contracts." The Journal of Industrial Economics, 48(1): 103-135.

Anton, James J. and Dennis A. Yao. 1994. "Expropriation and Inventions: Appropriable Rents in the Absence of Property Rights." The American Economic Review, 84(1): 190-209.

Anton, James J. and Dennis A. Yao. 2002. "The Sale of Ideas: Strategic Disclosure, Property Rights and Contracting." The Review of Economic Studies, 69(3): 513-531.

Arora, Ashish, Andrea Fosfuri and Alfonso Gambardella. 2002. Markets for Technology: the Economics of Innovation and Corporate Strategy. The MIT Press.

Arora, Ashish and Andrea Fosfuri. 2003. "Licensing the Market for Technologies." Journal of Economic Behavior and Organization, 52(2): 277-295.

Benoit, Jean-Pierre. 1985. "Innovation and Imitation in a Duopoly." Review of Economic Studies, 52(1): 99-106.

Bernheim, Douglas. 1984. "Strategic Deterrence of Sequential Entry into an Industry." RAND Journal of Economics, 15(1): 1-11.

Bessen, James. 2005. "Patents and the Diffusion of Technical Information," Economics Letters, 86: 121-128.

Boldrin, Michele and David Levine. 2002. "The Case Against Intellectual Property." The American Economic Review Papers and Proceedings, 92(2): 209-212.

Boldrin, Michele and David Levine. 2005. "Intellectual Property and the Efficient Allocation of Surplus from Creation." Review of Economic Research on Copyright Issues, 2(1): 45-67

Boldrin, Michele and David Levine. 2008. "Perfectly Competitive Innovation." Journal of Monetary Economics, 55(3): 435-453. 
Boldrin, Michele and David Levine. 2010. "Appropriation and Intellectual Property." Working Paper.

Bolton, Patrick and Joseph Farrell. 1990. "Decentralization, Duplication, and Delay." The Journal of Political Economy, 98 (4): 803-826.

Choi, Jay Pil. 1998. "Patent Litigation as an Information-Transmission Mechanism." The American Economic Review, 88(5): 1249-1263.

Cohen, Wesley, Richard Nelson and John Walsh. 2000. "Protecting Their Intellectual Assets: Appropriability Conditions and Why US Manufacturing Firms Patent (or not)." NBER Working Paper.

Contractor Farok J. 1985. Licensing in International Strategy. Westport, Conn.: Quorum Books.

Davidson, Carl and Paul Segertrom. 1998. " $R \& D$ subsidies and Economic Growth," The Rand Journal of Economics, 29(3): 548-577.

Fudenberg, Drew and Jean Tirole. 1991. Game Theory. The MIT Press.

Gallini, Nancy T. 1984. "Deterrence by Market Sharing: A Strategic Incentive for Licensing" The American Economic Review, 74(5): 931-941

Gallini, Nancy T. 2002. "The Economics of Patents: Lessons from Recent U.S. Patent Reform," Journal of Economic Perspectives, 16:131-154.

Gallini, Nancy T and Suzanne Scotchmer. 2001. "Intellectual Property: When Is It the Best Incentive System?" in A. Jaffe, J. Lerner, and S. Stern. eds. Innovation Policy and the Economy, Vol. 2. Cambridge, MA: MIT Press.

Grossman, Gene and Elhanan Helpman. 1991. "Quality Ladders and Product Cycles," The Quarterly Journal of Economics, 106(2): 557-586.

Harris, Bryan. 1997. "Technology Licensing in the European Union," The Journal of Law and Technology, 38: 139-154.

Hendricks, Kenneth, Andrew Weiss and Charles Wilson. 1988. "The War of Attrition in Continuous Time with Complete Information" International Economic Review, 29(4): 663-680.

Lanjow, Jean. 1998. "The Introduction of Pharmaceutical Product Patents in India: Heartless Exploitation of the Poor and Suffering?" NBER Working Paper No W6366

Muto, Shigeo. 1986. "An Information Good Market with Symmetric Externalities" Econometrica, 54(2): 295-312.

Rockett, Katharine. 1990. "Choosing the Competition and Patent Licensing" RAND Journal of Economics, 21(1): 161-171.

Rostoker, Michael D. 1983. "PTC Research Report: A Survey of Corporate Licensing." Idea-The Journal of Law and Technology, 24: 59-91. 
Scherer, Frederic and David Ross. 1980. Industrial Market Structure and Economic Performance. Houghton Mifflin Company.

Segerstrom, Paul. 1991. "Innovation, Imitation and Economic Growth." The Journal of Political Economy, 99(4): 807-827.

Smith, Maynard. 1974. "The Theory of Games and Evolution in Animal Conflicts." Journal of Theoretical Biology, 47: 209-221. 